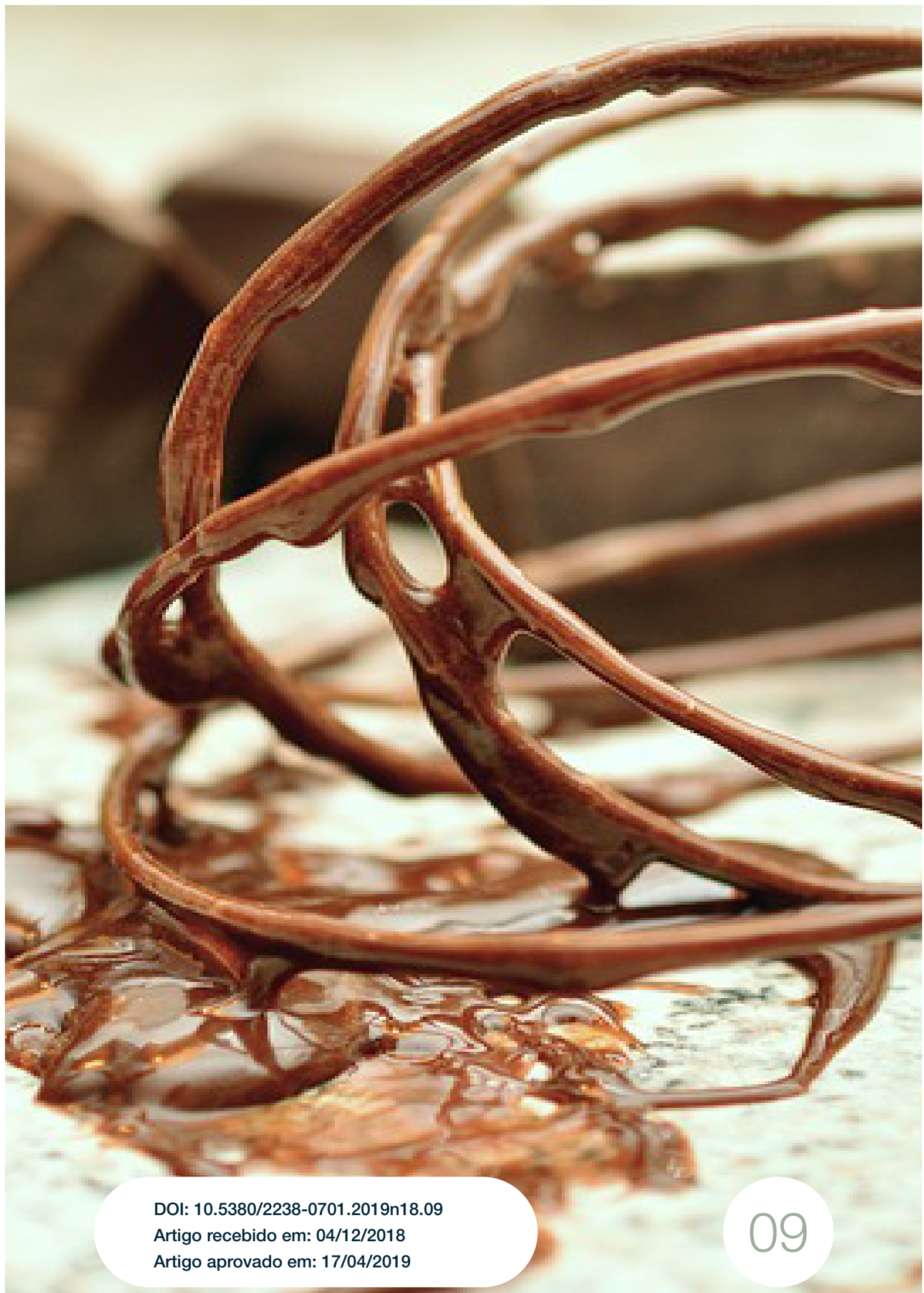


Doce, proibido, tentador: A quaternidade mítica e o papel da comida no filme CHOCOLATE 


\title{
Doce, proibido, tentador: A quaternidade mítica e o papel da comida no filme CHOCOLATE
}

\author{
Sweet, forbidden, tempting: \\ The mythical quaternity and the role of food \\ movie in the chocolate \\ Dulce, prohibido, tentador: \\ La quaternidad mítica y el papel de la comida \\ en la película chocolate \\ ARTHUR CARLOS FRANCO OLIVEIRA \\ HERTZ WENDEL DE CAMARGO ${ }^{2}$ \\ Resumo: O presente trabalho busca analisar, sob a ótica da teoria \\ da quaternidade mítica proposta por Canevacci (1990), o papel \\ da comida e o seu poder impulsionador da sociabilidade no filme \\ Chocolate (Lasse Hallström, 2000). Partindo da metodologia de \\ análise fílmica proposta por Vanoye e Goliot-Lété (1994), busca- \\ mos identificar no componente diegético do filme os vínculos dos
}

\footnotetext{
1 Mestrando em Comunicação pela Universidade Federal do Paraná - PPGCOM - UFPR, bolsista CAPES. E-mail: arthurcfranco@gmail.com.

2 Doutor em Estudos da Linguagem e professor do Mestrado em Comunicação da Universidade Federal do Paraná. E-mail: hertzwendel@gmail.com.
} 
personagens com o chocolate, por meio de um referencial teórico que encara a comida como objeto de ligação social e mediador das práticas entre os sujeitos. As relações entre os arquétipos propostos por Canevacci (1990) são moldadas e modificadas pela inserção do chocolate e suas significações no ambiente conservador da obra, já que o doce atua como item de desejo, repulsa, pecado e modificação gregária e identitária ao longo do filme. Os resultados indicam a quaternidade mítica como elemento coesivo da estrutura diegética do filme, com evidente destaque para a capacidade dos hábitos alimentares de criar, reafirmar e reorganizar comportamentos.

Palavra-chave: Canevacci; Chocolate; Comida; Filme; Mito.

Abstract: The present paper seeks to analyze the role of food and its power to promote sociability in the film Chocolate (Lasse Hallström, 2000), parting from the point of view of the mythical quaternity theory proposed by Canevacci (1990). Based on the methodology of film analysis proposed by Vanoye and Goliot-Lété (1994), we seek to identify the relations of the characters with chocolate, through a theoretical framework that regards food as an object of social connection and mediator of practices among subjects. The relations between the archetypes proposed by Canevacci (1990) are shaped and modified by the insertion of the chocolate and its significations in the conservative environment of the movie, since the candy acts as an item of desire, repulsion, sin and gregarious, and identity modification throughout the film. The results indicate the mythical quaternity as a cohesive element of the diegetic structure of the film, with evident emphasis on the ability of eating habits to create, reaffirm and reorganize behaviors.

Keywords: Canevacci; Chocolate; Food; Movie; Myth.

Resumen: El presente trabajo busca analizar, bajo la óptica de la teoría de la cuaternidad mítica propuesta por Canevacci (1990), el papel de la comida y su poder impulsor de la sociabilidad en la película Chocolate (Lasse Hallström, 2000). A partir de la metodología de análisis fílmico propuesta por Vanoye y Goliot-Lété 
(1994), buscamos identificar las relaciones de los personajes con el chocolate, a través de un referencial teórico que encara la comida como objeto de vínculo social y mediador de las prácticas entre los sujetos. Las relaciones entre los arquetipos propuestos por $\mathrm{Ca}$ nevacci (1990) son moldeadas y modificadas por la inserción del chocolate y sus significaciones en el ambiente conservador de la obra, ya que el dulce actúa como ítem de deseo, repulsa, pecado y modificación gregaria e identitaria a lo largo de la película. Los resultados indican la cuaternidad mítica como elemento cohesivo de la estructura diegética de la película, con evidente destaque para la capacidad de los hábitos alimentarios de crear, reafirmar y reorganizar comportamientos.

Palabras-clave: Canevacci; Chocolate; Comida; Película; Mito.

\section{Plantando o cacau}

O cinema, analisado como produto cultural moldado pelo homem e, ao mesmo tempo, moldador da sociedade, pode ser encarado como um item de consumo capaz de apresentar a realidade de forma quase análoga, de certo modo formando uma impressão de realidade nos espectadores. A análise dos rituais presentes na construção fílmica oriundos da indústria cinematográfica permite elaborar inferências sobre comportamentos e posicionamentos culturais que, de certo modo, transitam entre a natureza dual do sujeito, representando tanto os aspectos culturais quanto os biológicos. A partir do consumo de material cinematográfico, o homem organiza seu universo simbólico tanto em nível individual quanto coletivo, por meio da percepção de outras vivências e ideais simbólicos presentes nos filmes na forma de ideologias, arte e concepções societárias. Apesar de se apresentar em grande variedade de forma e gênero, o cinema também possui em seu cerne a persistência de certas estruturas sistemáticas que se repetem a cada nova narrativa contada, além de seu consumo ocorrer em um ambiente quase sagrado. A diminuição das luzes, o silêncio requerido e a disposição de todos os olhares voltados para o sacerdote supremo, aqui representado pela tela iluminada como o verdadeiro altar da cerimônia, traduzem de forma emblemática um ritual quase 
que religioso.

As práticas e os modos da alimentação humana também são um fenômeno biocultural, agregando elementos tanto da natureza biológica dos indivíduos quanto das convenções culturais da sociedade. Analisar de que forma e em quais matrizes a alimentação é estabelecida se apresenta como campo que permite inferências sobre a relação dos sujeitos e sobre a organização social em que eles estão incluídos, já que diferentes sociedades têm diferentes formas de sistematização alimentar. Com efeito, o nosso objeto de estudo é o filme Chocolate lançado em 2000, com direção de Lasse Hallström, nomeado a cinco Óscares -, que tem a comida e seu papel social como condutor da sua estrutura diegética. Lasse Hallström é conhecido por dirigir grande parte dos videoclipes do grupo sueco Abba, e Chocolate foi o seu primeiro filme a ter a alimentação como argumento principal, tendo o diretor utilizado tal temática novamente em A 100 Passos de um Sonho (2014).

O universo cinematográfico emprega recorrentemente as práticas do sistema alimentar em suas narrativas. Dado o seu compartilhamento universal por todas as sociedades, a comida é um elemento utilizado como mote para debater os mais diversos aspectos da natureza humana nas telas do cinema, com alguns filmes tornando-se marcos na relação entre gastronomia e longas-metragens. Clássicos como A festa de Babette (Gabriel Axel, 1987), O Cozinheiro, o Ladrão, sua Mulher e o Amante (Peter Greenaway, 1989) e Comer Beber Viver (Ang Lee, 1994) mostram a alimentação em suas inúmeras facetas, atuando como agente de sociabilidade, identidade, afetos e multiculturalismos. Os aspectos da vida profissional daqueles que elegeram a gastronomia como profissão são mostrados em longas como Vatel - Um banquete para o rei (Roland Joffé, 2000), Simplesmente Martha (Sandra Nettelbeck, 2001) e Julie \& Julia (Nora Ephron, 2009), os quais abordam as transformações dos alimentos no plano simbólico como metáforas para mudanças na vida dos personagens, e como a comida não nutre apenas o corpo biológico, mas também nutre o imaginário e as relações pessoais. No campo da animação, as práticas do sistema alimentar também se apresentam como agente potencializador de alterações na natureza dos personagens, atuando como a grande protagonista em Ratatouille (Brad Bird, 2007) e assinalando o alimento como um agente 
de transformação da natureza em cultura em $A$ viagem de Chihiro (Hayao Miyazaki, 2001).

Para a análise, utilizamos a metodologia de análise fílmica proposta por Vanoye e Goliot-Lété (1994), que permite decompor o produto audiovisual e isolar elementos da narrativa para compreender como se dá a sua relação com o todo, o que possibilita depreender elementos por vezes não perceptíveis a "olho nu". Essa metodologia se propõe a desagrupar o mise en scène que compõe o filme, isolando os elementos estéticos, narrativos, sonoros e sequenciais, entre outros, a fim de realizar uma segmentação que permite estudar o componente escolhido em sua individualidade e na totalidade com a obra. Dentro das inúmeras possibilidades analíticas que um filme permite, decidimos isolar o componente diegético do longa-metragem em detrimento aos enfoques técnicos, abordando os aspectos narratológicos do enredo que envolvem como a trama é desenvolvida e de que forma a narrativa expõe os personagens e as situações que acarretam em seu desenvolvimento e transformação pessoal e social. Assim, assistimos ao filme observando de que maneira o roteiro é construído e a narrativa contada, investigando ações e dinâmicas dos personagens que permitissem identificar os arquétipos propostos por Canevacci (1990) e perceber como a organização alimentar é traduzida em segmentos que colocam a estrutura diegética em movimento. Justamente pela divisão do filme em partes menores como proposto pela análise fílmica, escolhemos a quaternidade mítica como complemento metodológico, já que, por meio da identificação dos arquétipos de Pater, Filius, Diabolus e Spiritus, é possível perceber como diferentes personagens interagem entre si e de que maneira a narrativa é fundamentada. Tais elementos atuam diretamente sobre a construção diegética do filme e impelem-na a desenrolar-se, e sua decomposição permite a análise de como o filme se estrutura em nível de roteiro e de arranjo expositivo da trajetória percorrida pelos personagens. A escolha da análise apenas do roteiro e das questões narratológicas em detrimento aos detalhes técnicos da montagem do filme se deu pelo fato de que, ao buscar entender a dinâmica do sistema alimentar presente dentro do filme, o enredo e a forma como ele é desenvolvido se mostrarem muito mais profícuos para a percepção das relações sociais mediadas pela alimentação do que pelo fato de como as cenas são montadas 
tecnicamente. O arranjo físico da cena, no nosso caso, não traz tantos elementos de significativa influência de como as práticas alimentares são construídas quanto aqueles contidos na própria dinâmica diegética entre os personagens e o sistema alimentar.

\section{Temperando o chocolate}

Canevacci (1990) entende o cinema como "o máximo produtor de ideologias mercantilizadas do século XX” (p. 22) e defende que o cinema é, por si só, antropológico, já que tem por si a possibilidade de representar qualquer narrativa histórico-cultural situada no espaçotempo da humanidade, além de poder influenciar comportamentos e organizar hábitos por meio de estruturas diegéticas. Conforme mencionamos antes, a estrutura quase religiosa presente no âmbito do consumo fílmico se traduz em uma matriz predominantemente cristã, o que permitiu que Canevacci (1990) apresentasse uma antropologia fílmica que explicita a presença sistemática de arquétipos baseados em uma quaternidade mítica.

Assim, desponta uma antropologia que se insere no estudo não só da infra e superestrutura da sociedade, mas também no que Canevacci (1990) chama de hipo-estrutura, uma estrutura mítica presente no imaginário coletivo que apresenta fundamentos da cultura cristã-burguesa imbuídos na cultura de massa. No final do século XIX, as pesquisas envolvendo a reprodução de imagens em movimento estavam avançadas, e a burguesia viu nessa nova forma de arte um meio para difundir sua ideologia de forma não explicita, mas sempre a reafirmando como verdade. A difusão e consequente popularização do cinema se deram pela possibilidade da produção de cópias dos filmes, feitas a baixo custo, tornando assim o cinema uma mercadoria, na qual o espectador adquire o direito de usufruir momentaneamente, fazendo então uma aposta no escuro quanto ao filme, pois não existe possibilidade de retorno ou troca dessa mercadoria. O cinema, para Canevacci (1990), é um ritual comparável à missa, na qual a mesma história sempre se repete com o eterno mito do nascimento, da escolha e da afirmação do herói, a sua morte por sacrifício até a sua ressureição. Com efeito, o cinema adota tanto uma linguagem quanto uma narrativa 
compreensíveis ao grande público, estrutura essa reconhecível por vezes não no nível consciente e lúcido, mas mediante os contextos há muito difundidos nos mitos enraizados na cultura e na religião. $\mathrm{O}$ cinema, então, utilizando-se dos elementos presentes na hipo-estrutura e na cultura cristã-burguesa, guia-se no contínuo preenchimento do esquema quaternário em suas narrativas, conjugando os quatro princípios da cruz arquetípica representada abaixo.

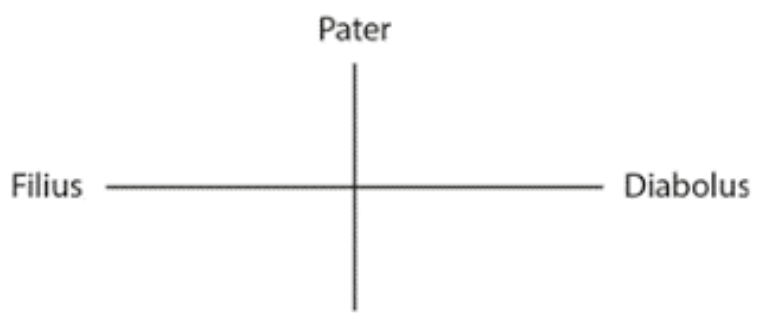

Spiritus

Canevacci (1990) nos dá detalhes do que cada elemento se constitui e de como eles se encontram presentes e coordenam a narrativa cinematográfica. Passemos então à definição resumida de cada um dos elementos para, a seguir, entender como eles se encaixam no objeto analisado.

Pater: é ao mesmo tempo a origem de todas as coisas quanto a determinação socio-histórico do ser, representando o superego e, de qualquer ponto de vista, representa o poder. Representa a origem de tudo, é o elemento que dá início à narrativa.

Filius: é representado pelo ego, a epítome do herói,

representa um status intermediário, de passagem, que encontra sua origem no Pater, e sua finalidade em se tornar, por seu turno, sempre Pater: e, com efeito, a viagem é a sua condição normal na ordem de narração. Ele viaja no conflito, dentro do esplendor e da miséria do sensível, as provas que deve superar servem para conquistar a meta da consciência individual e da racionalidade. (CANEVACCI, 1990, p 57).

Em resumo, o Filius é o elemento que passa por um processo transitório, a viagem, buscando retomar ao status inicial, porém, agora provido de autoconsciência, de entendimento racional e dilatado. Tem como seu desígnio final se tornar Pater, o qual é sua origem e provisor de força. Exemplos são Odisseu e Cristo, protagonistas de jornadas 
das quais renascem mais desenvolvidos e dotados de consciência florescente.

Diabolus: é o oposto ao Filius, o anti-herói, a sombra, "zona indistinta e incontrolada, pulsionante e rebelde do id” (CANEVACCI, 1990, p. 58). É oposto absolutamente também ao Pater, mas encontra no Filius o seu contemporâneo. Na religião, é Satanás; na epopeia, as provações que Odisseu enfrentou: Circe, os Comedores de Lótus, A Sereia, O Ciclope.

Spiritus: representa a concordância entre o Filius e o Diabolus, sendo seu âmago feminino, na lembrança da mãe, da origem do Espírito Santo na Santíssima Trindade, o elemento irracional e irrefletido. Devido à sua essência feminina e dualística, tanto tem o instinto materno de proteger Filius e com ele derrotar Diabolus quanto o aspecto de fêmea sedutora cuja "histeria binária de sua natureza feminina leva-o aos braços de Diabolus. Aliás, é seu alter-ego, nas formas de tentação" (CANEVACCI, 1990, p. 58).

Canevacci deixa bem claro que seu intuito não é propor uma fórmula que explique e se encaixe em todos os filmes, mas sim explicitar que esse modelo quaternário estabeleceu os estilos de vida de forma mais incisiva e acentuada por meio da repetição de ciclos e representações mitológicas presentes no imaginário coletivo. Assim, as estruturas arquetípicas presentes na ideologia cristã-burguesa se infiltraram no cinema, cuja estrutura diegética busca reproduzir essas imagens míticas para que sejam incorporadas pelo espectador de forma orgânica.

\section{Degustando o chocolate}

O filme Chocolate começa com uma narração evidenciando que, naquele pequeno vilarejo onde a história se passa, a tradição e os costumes têm papel fundamental na sistematização e na continuidade da organização social, narração essa que preludia o embate entre as normas tradicionais e a inovação que se desenrolará ao longo do filme. Com efeito, encontramos a protagonista Vianne Rocher chegando com sua filha Anouk a um vilarejo francês no ano de 1959, e, apesar de ser o início da Quaresma e do período de jejum dos moradores, ela abre ali uma chocolateria. Vianne parece representar tudo que os habitantes abominam: é ateia, muda de cidade constantemente, é mãe solteira 
de uma filha ilegítima, e tem uma perspectiva otimista sobre sua loja, apesar de receber reprovações dos moradores, principalmente do defensor primário dos bons costumes, o prefeito Comte de Reynaud. Aos poucos, os residentes vão abrindo-se e sendo conquistados por Vianne, sendo Yvette a primeira. Infeliz na vida sexual, ela resolve acatar a sugestão de Vianne em oferecer pedaços de cacau a seu marido, e vê sua afetuosidade conjugal melhorada, inclusive voltando à chocolateria para buscar mais cacau.

Tomamos conhecimento do casamento fracassado do prefeito, o qual se mostra interessado em sua secretária e que foi abandonado por sua esposa que está passando uma longa temporada em Veneza. Também vemos a transformação de Armande, uma senhora impedida pela própria filha de ver o neto, e que num primeiro momento se mostra amargurada e ríspida, mas aos poucos vai tornando-se amável, como que se tivesse o coração aquecido pelo chocolate quente com pimenta servido por Vianne. Armande tem uma reaproximação com o neto por intermédio da protagonista, que organiza encontros entre os dois em sua loja. Outra personagem que tem sua existência mudada pela chocolatier é Josephine, uma cleptomaníaca que sofre abusos físicos do marido e acredita que todos da cidade estão contra ela. Após seu marido agredi-la uma noite, ela se muda para a casa de Vianne, a qual a ensina o ofício do chocolate, transformando Josephine completamente, agora uma mulher dona de si e confiante. Apesar da conquista afetiva de alguns habitantes, sempre por meio do chocolate, o embate entre Vianne e Reynaud continua crescente, até que um bando de ciganos chega à cidade em barcos e monta acampamento à beira do rio. A protagonista acaba dormindo com um dos ciganos, Roux, em seu barco, o qual é colocado em chamas pelo ex-marido de Josephine, causando a partida dos ciganos. Tal ato causa sua expulsão da cidade, pois aquela demonstração de ódio foi demais até mesmo para o prefeito Reynaud. Vianne, exausta de ser confrontada e ofendida, resolve se mudar novamente, apesar da relutância de Anouk. Prestes a partir, ela passa pela cozinha e encontra um grupo de moradores, inclusive com aqueles que anteriormente não simpatizavam com ela, fazendo chocolates para o Festival da Páscoa que Vianne tinha planejado, atitude essa reflexo do carinho e da mudança que a protagonista e seus chocolates causaram em todos. Apesar disso, o prefeito ainda é relutante com Vianne, e 
invade a loja na noite anterior ao festival com o intuito de destruir os chocolates da vitrine. Acidentalmente, ele prova o chocolate, cedendo então à tentação e comendo grande parte dos chocolates até pegar no sono na vitrine da loja. Pela manhã, o prefeito e Vianne fazem as pazes, com o Festival sendo um sucesso. A história pula então para o próximo verão, em que vemos Reynaud, agora mudado e casado com sua secretária, e Vianne ainda morando no vilarejo, agora casada com Roux, e com sua chocolateria ainda aberta.

As delimitações da quaternidade mítica consideradas por Canevacci (1990) encontram respectivas correspondências no filme Chocolate, resultando no seguinte esquema:

Figura 1 - A quaternidade mítica no filme Chocolate

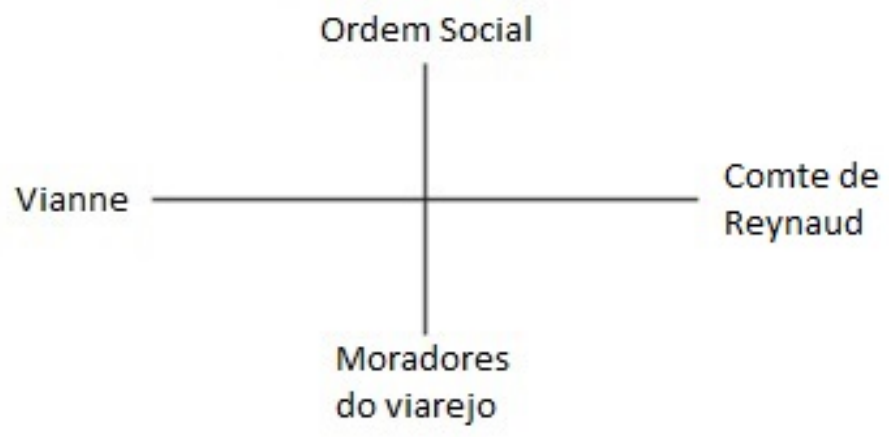

Fonte: elaborado pelo autor.

Pater aqui é representado pela ordem social, pelas práticas que regulam e permeiam a vida em conjunto, e que estipulam funções e o papel de cada um ali incluído. A alimentação tem grande destaque nessa delimitação e propagação das posições sociais, já que os alimentos e seus modos de consumo carregam consigo determinados simbolismos que afetam como os sujeitos lidam tanto com eles quanto com a sociedade. Com efeito, o ato de se alimentar é um fenômeno biocultural, que passa por um sistema de escolhas e implicações, tanto no plano físico em relação à disponibilidade dos alimentos quanto no sentido cultural. Essa dualidade se traduz na percepção social, já que 
o homem não vem geneticamente preparado para a vida social; ele necessita dos elementos culturais para informar sua ação. Por isso, precisa estar inserido num processo simbólico, do qual é criador e criatura. É esse processo que vai lhe dizer, por exemplo, o quê, quando, com quem, onde e como deve comer. Isso é muito mais complexo do que simplesmente satisfazer o instinto da fome. Entretanto, este último desempenha um papel importante em relação ao sistema simbólico. É da dinâmica entre ambos que se atualizam os hábitos alimentares. Por isso, é correto dizer que o alimento carrega um valor ao mesmo tempo utilitário e simbólico. (DANIEL; CRAVO, 2005, p. 67).

A polarização entre cultural e biológico segue uma linha de pensamento que guia o estudo das ciências sociais e das ciências naturais, criando paralelismos como cru e cozido, corpo e espírito, físico e metafísico. A ideia de civilização e, por conseguinte, de ordem social, passa pela possibilidade da modificação de alimentos pelo fogo. Este permitiu uma transformação profunda tanto nos modos biológicos de nos alimentarmos, já que a digestão foi facilitada pelo cozimento, quanto permitiu que os primeiros homens estabelecessem laços e rituais de sociabilidade ao redor do fogo. O uso do fogo e o advento de regras de comensalidade estritas nos distinguiram veementemente dos animais, já que "a ritualização das refeições e a corporificação de seus elementos, que incluíam o uso da faca e do garfo, como cortar, como proceder à mesa, foram sendo convertidos em boas maneiras e meios de distinção social, ilustrando o processo civilizador do homem ocidental" (MOREIRA, 2010, p. 23).

Logo, as relações humanas em sociedade e o consequente advento e manutenção de uma ordem regulatória social são atravessadas pela relação dicotômica alimentar entre biológico e cultural. Essas regras tanto moldam quanto são moldadas pelas diferentes instituições e identidades humanas, variando tanto no espaço quanto no tempo, e entre os diferentes tipos de classificação social, como gênero, idade e situação profissional. A carne, por exemplo, é um alimento que durante boa parte da história humana se constituiu um elemento tanto de distinção social quanto de identidade. Especialmente durante a Baixa Idade Média, apenas as classes mais abastadas tinham acesso a ela, restando aos camponeses uma alimentação baseada em papas 
e vegetais, sem a possibilidade da caça (FLANDRIN; MONTANARI, 1998). Mesmo em tempos atuais, ainda vemos um acesso muito mais irrestrito à carne e a diversos outros insumos a classes mais abastadas, enquanto alguns alimentos ainda têm o seu consumo relacionado aos sujeitos com menor poder aquisitivo. Assim, entendemos que as práticas alimentares estão intimamente vinculadas à ordem social, crença que encontra ampla representação no filme Chocolate.

Vianne, introduzindo os chocolates e toda a simbologia neles embutida no pequeno vilarejo, consegue causar uma grande mudança na tradicional ordem social. Ela representa o Filius da cruz quaternária de Canevacci (1990), que passa por diversos passos da tradicional Jornada do Herói, como provação, ressureição e expansão da consciência. Sua relação com o alimento símbolo do filme, o chocolate, não só altera a dinâmica do vilarejo, mas também a si mesma. Se antes vivia em constante nomadismo, após abrir a chocolateria e modificar a vida de diversos personagens, Vianne decide ali estabelecer moradia fixa. Mediante simbolismos e metáforas traduzidas no chocolate e na percepção social deste, encontramos uma relação entre alimentação e identidade muito presente no filme.

A escolha dos alimentos consumidos, os seus modos de preparo e os rituais de comensalidade que os cercam permitem marcar as diferenças e particularidades culturais de um determinado grupo. A Brillat-Savarin, autor do livro A Fisiologia do Gosto publicado no século XIX e que modificou a percepção da literatura gastronômica, é atribuído o ditado que representa a epítome da correlação entre cultura, "digame o que comes que te direi quem és". Cada grupo de indivíduos possui em seu corpo de regras, que na maioria das vezes não são escritas, mas sim transmitidas por meio dos costumes e das práticas, esquemas de referências que orientam a escolha do que e como comer. Como evidenciado por Contreras e Gracia (2015), algumas predileções são compartilhadas por outros grupos, já algumas são exclusivas e identificam socialmente aquele agrupamento. A percepção dessas escolhas se dá majoritariamente na relação de diferença com o outro, pelo entendimento que se possui determinada identidade porque se consume tal coisa, enquanto essa identidade é negada ao outro por não consumir o mesmo. Essa sensação de pertencimento se dá em todos os aspectos da cultura, e não apenas no campo da alimentação, mas 
encontra forte expoente neste, já que ela é uma necessidade fisiológica. Com efeito,

há exemplos que mostram que os seres humanos marcam tal pertencimento mediante a afirmação de sua peculiaridade alimentar diante e em contraste com aquela 'dos outros'. A comida é um importante elemento utilizado pelos grupos sociais para tomarem consciência de sua diferença e de sua etnicidade - vista como o sentimento de fazer parte de uma entidade cultural diferente -, de maneira que compartilhar pode significar o reconhecimento e a aceitação/incorporação de tais diferenças. (CONTRERAS; GRACIA, 2015, p. 141).

Diversos aspectos, sejam eles materiais, econômicos, sociais ou ideológicos, influenciam a construção de identidades por meio das práticas alimentares. Dessa forma, podemos resumir que o que comemos é um dos fatores que reflete nosso papel na sociedade e como nos apresentamos perante os outros. Essa representação encontra ressonância em Vianne e na sua identidade. São vários os fatos permeados pela identidade alimentar, tanto sua quanto dos outros cidadãos, que a distingue deles. Em primeiro lugar ela é ateia, enquanto todos os outros moradores são católicos e estão respeitando o tempo da Quaresma. É um tempo de contrição, de jejum e sacrifício, logo, não é o tempo de comer chocolates, mas Vianne abre sua loja bem no início da Quaresma. Ao não seguir a tradição do jejum, Vianne se mostra diferente dos outros habitantes, e seus hábitos configuram uma ameaça aos valores culturais ali já há muito estabelecidos e seguidos sem qualquer questionamento. Aos poucos a identidade tida como imutável vai sofrendo alterações, e o chocolate, visto então como o grande vilão e agente tentador do Diabo, transforma-se em um alimento corriqueiro que passa a fazer parte das escolhas alimentares daquele grupo. A mudança de paradigma quanto ao chocolate, aliado a outras atitudes de Vianne (sempre relacionadas ao chocolate), permitiram que ela fosse incluída na comunidade, estabelecendo a relação entre pertencimento e identificação social que se funda em grande parte na alimentação, já que "o que é colocado no prato serve para nutrir o corpo, mas também sinaliza um pertencimento, servindo como um código de reconhecimento social” (MACIEL, 2005, p. 54).

Em Chocolate, o arquétipo de Spiritus encontra ressonância nos 
moradores do pequeno vilarejo, enquanto o Diabolus é o prefeito Comte de Reynaud. Os moradores, ao passo que são atraídos pela loja e pela tentação de quebrar o jejum e degustar os chocolates, também obedecem às normas morais ditadas pelo prefeito. Assim, devido à sua essência dual, o Spiritus leva Vianne a ser bem-sucedida ao estabelecerem ligações amistosas com ela, ao passo que, ao fazer isso, também a empurra para um confronto cada vez mais iminente com o Diabolus. A relação entre Vianne e os outros moradores tem como mediador o chocolate, e toda a carga simbólica embutida a ele no filme. Ele é o elemento de coesão entre o Spiritus e o Filius, o agente que transita entre os protagonistas estabelecendo vínculos entre os sujeitos, e também criador de tensão na trama. A forma com que os moradores são atraídos e repelidos em sua relação com Vianne encontra um viés simbólico que permite explicar a organização das sociedades por meio de seus rituais alimentares.

A comida e seus modos de preparo e comensalidade, como supracitado, são objetos de identificação ou de estranhamento entre os sujeitos, e representam um dos aspectos da formação ou não de comunidades. Assim,

o alimento por si só é usado simbolicamente para representar certas formas sociais e sentimentos pessoais dentro de uma sociedade, que geralmente figuram entre as formas e os sentimentos pessoais importantes na vida do grupo. Assim, observando os contextos sociais específicos e limitados (clã, aldeia, relações de parentesco, político, amizade, vizinhança, relações de trabalho etc.) dentro dos quais são empregados simbolicamente os alimentos, pode-se, com frequência, inferir quais são os grupos e relações importantes na sociedade. (CONTRERAS; GRACIA, 2015, p. 193).

É importante atentar que as regras de distribuição de alimentos em uma sociedade, segundo Contreras e Gracia (2015), são formas de representar e reforçar as estruturas éticas e morais vigentes. A comida é um meio de refletir hospitalidade e sociabilidade em diversas sociedades, e a proximidade dos relacionamentos entre os sujeitos pode ser entendido mediante análise dos tipos de alimentos que eles trocam entre si, e das refeições que compartilham, no sentido de que "a comida é oferecida como um gesto de amizade e, quanto mais 
elaborada for, maior é a intimidade que expressa ou maior é o grau de estima ou também de interesse" (CONTRERAS; GRACIA, 2015, p. 195). Assim, compartilhar a mesa e a refeição é um indicativo de pertencimento e de amizade, bem como, pela lógica da oposição, é um espaço de marginalização e segregação. O convite para o compartilhamento dos alimentos em conjunto expressa a partilha de experiências que cria vínculos afetivos, enquanto a negação da repartição e da mesa reflete o não pertencimento e o desejo de não se relacionar. Vemos essa distinção claramente em Chocolate, por meio da evolução da relação de Vianne com os outros personagens. No início da narrativa, eles rechaçam Vianne e os produtos que ela oferece, pois aquele não é o tempo para comer chocolates, além de ela representar a oposição a todos os ideais ali seguidos. Essa negação do chocolate reflete a negação da interação social com a própria protagonista, que é alvo de olhares e comentários maldosos. No decorrer do filme, a partir das habilidades e da persistência de Vianne, os moradores vão cedendo pouco a pouco a seus chocolates, e, consequentemente, ao convívio com ela, estabelecendo laços afetivos e gregários, até o ponto de literalmente compartilharem uma refeição sentados à mesa no aniversário de Armande. Após o próprio prefeito, que representa a epítome do conservadorismo e das convenções sociais, entregar-se ao chocolate, a sociabilidade com a protagonista encontra seu ápice por meio do bem sucedido festival do chocolate promovido por Vianne, representando que agora ela é parte integrante da comunidade e não mais alvo de desconfiança. A criação desse vínculo social por intermédio da comida reflete o afeto e a intimidade emocional desenvolvida, já que "até certo ponto, pode-se pensar que oferecer compartilhar a refeição própria é ofertar um pouco ou uma mordida de si próprio" (CONTRERAS; GRACIA, 2015, p.195).

A mudança de paradigma na alimentação e nas proibições de consumo mostram o quanto a sociedade e as relações foram afetadas pela introdução do chocolate, explicitando a conexão de que "quando são atacadas as proibições referentes ao consumo de alimentos, podese supor que estão ocorrendo mudanças significativas na estrutura socioeconômica da sociedade correspondente" (CONTRERAS; GRACIA, 2015, p. 193). A negação de Vianne e do seu modo de vida, ao continuarem firmes aos preceitos religiosos do vilarejo, contrastam 
com a progressiva tentação e o desejo de consumir seus chocolates, concretizando a relação dual que é característica de Spiritus e sua essência de repelir e abraçar Filius.

Por fim, Diabolus encontra sua representação no prefeito do vilarejo, que desde o início da trama é contra o chocolate, e compele todos os outros a seguirem o sacrifício e o jejum característicos da Quaresma. Oposto a Filius, o prefeito é o inverso de Vianne, por si uma personagem de espírito livre, alegre e calorosa que usa roupas de cores vibrantes, enquanto Comte de Reynaud é sisudo, fechado e dedicado a respeitar as regras e tradições da comunidade. Optando por fazer jejum rígido, ele espera que todos os outros habitantes sigam a tradição cristã, e que cada um se preserve na rigorosa função social já delimitada. A proibição do consumo de alimentos, sobretudo do chocolate, reflete a percepção dual que por vezes a comida recebe, representando

\begin{abstract}
uma ambivalência profunda: é fonte de intenso prazer, mas é também fonte de sofrimento. Essa dualidade também apresenta traços culturais: nem todas as sociedades sentem o mesmo pela comida, e a comida pode ser diferentes coisas. As atitudes diante dos alimentos são tanto numerosas quanto variadas e se manifestam ao expressar o que significa comer, de que nos serve ou para que comemos. (CONTRERA; GRACIA, 2015, p. 146).
\end{abstract}

A Quaresma é um período de se fazer penitência com intuito de obter a purificação e de expurgar os pecados. Nas culturas que tem como base a cultura cristã, certos alimentos e o seu consumo são imbuídos de significações de pecado ou como uma forma de atingir a santidade. Na Idade Média, os dias de abstenção de carne eram vários durante a semana, alimentos como aves eram considerados mais santificados e leves pelo fato de voarem, e, consequentemente, estarem mais perto de Deus (MONTANARI, 2013); e os monges deviam excluir total ou parcialmente a carne de suas dietas devido à associação desse alimento ao guerreiro, à brutalidade e à força. Assim, os alimentos carregam simbolismos ditados pela cultura cristã como bons ou maus, e o chocolate, por ser doce e fonte de prazer, representa a quebra do martírio e da penitência característicos da Quaresma. Incutir características simbólicas em alimentos é uma forma de exercer controle e concretizar autoridade, mesmo que esses atributos por vezes sejam arbitrários e tragam consigo outras significações que não 
aquelas aparentes à superfície. Quando o prefeito proíbe o consumo do chocolate, sua intenção não é a proibição apenas no sentido físico, mas sim de todos os predicados que acompanham o alimento e quem o fabrica. Nesse sentido, a proibição carrega em si a perspectiva de que quem consumir o chocolate se entregará ao pecado e à conduta transgressora de Vianne, afastando-se dos ideais ditos cristãos.

\section{Considerações Finais}

As práticas e os modos alimentares constituem uma importante ferramenta na análise da constituição cultural e sistemática de uma sociedade. Por ser um fenômeno biocultural, a alimentação funciona como um elo que articula componentes orgânicos e biológicos da individualidade quanto da alteridade presentes no imaginário coletivo sobre a percepção alimentar e das normais sociais que a cercam.

A partir de uma análise fílmica e da aplicação do conceito de quaternidade mítica e seus desdobramentos proposto por Canevacci (1990), foi possível estabelecer os papéis míticos e arquetípicos atribuídos a cada personagem no filme Chocolate e explicar de que forma a relação entre comida, identidade, sociabilidade e pecado se articula. Assim, foi compreendido que a identidade de um grupo está fortemente ligada aos modos de preparo e à escolha dos alimentos, e que a partilha ou não dessas práticas se revela como um instrumento de comunhão e exclusão social. Também percebemos que a comida é procedência de um discernimento dualístico, sendo tanto fonte de prazer quanto possibilidade de pecado e transgressão, principalmente quando levado em conta o ambiente e as normais sociais e religiosas que cercam determinado alimento. É importante ressaltar que a análise aqui compreendida é uma das possíveis leituras feitas a partir da aplicação da teoria da quaternidade mítica ao filme. Por não se tratar de uma fórmula fechada aplicável de modo engessado aos objetos fílmicos, mas sim de uma linha de pensamento que permite diversos olhares a partir do universo simbólico do pesquisador e do viés escolhido para a investigação, diferentes acepções dos arquétipos propostos por 
Canevacci poderão ser encontradas examinando os personagens e as relações sociais representadas no filme a partir de uma leitura que leve em conta aspectos diferentes dos analisados aqui.

O presente estudo do filme Chocolate, sob a ótica da quaternidade mítica, faz parte de uma análise que será aprofundada na dissertação de mestrado do autor, na qual serão abordados a origem das matrizes arquetípicas propostas por Canevacci, os rituais midiáticos de consumo da comida e do cinema, assim como sua relação com outros três filmes que possuem a alimentação como temática principal.

\section{Referências}

BRILLAT-SAVARIN. A fisiologia do gosto. São Paulo: Companhia das Letras, 1995

CANEVACCI, Massimo. Antropologia do cinema. 2. ed. rev. e ampl. Editoria Brasiliense: São Paulo, 1990.

CONTRERAS, Jesús; GRACIA, Mabel. Alimentação, sociedade e cultura. Rio de Janeiro: Editora Fiocruz, 2015.

DANIEL Junbla Maria Pimentel; CRAVO Veraluz Zicarelli. Valor social e cultural da alimentação. In: Canesqui Ana Maria, Garcia Rosa Wanda Diez. organizadores. Antropologia e Nutrição: um diálogo possível. Rio de Janeiro: Editora Fiocruz; 2005. p. 57-68.

FLANDRIN, Jean-Louis \& MONTANARI, Massimo. História da Alimentação. São Paulo: Estação Liberdade, 1998.

MACIEL, Maria Eunice. Identidade Cultural e Alimentação. In: CANESQUI, Ana Maria \& Rosa Wanda Diez Garcia (orgs.). Antropologia e Nutrição: um diálogo possível. Coleção Antropologia e Saúde. Rio de Janeiro: Editora Fiocruz. 2005

MONTANARI, Massimo. Comida como cultura. 2. ed. São Paulo: Editora Senac, 2013.

MOREIRA, Sueli Aparecida. Alimentação e comensalidade: aspectos históricos e antropológicos. Ciência e Cultura, v. 62, p. 23-26, 2010.

VANOYE, Francis; GOLIOT-LÉTÉ, Anne. Ensaio sobre a análise fílmica. São Paulo: Papirus, 1994.

\section{Filmografia}

Chocolate. Direção de Lasse Hallström. EUA/Reino Unido: Imagem Filmes, 2000. 121 minutos. 


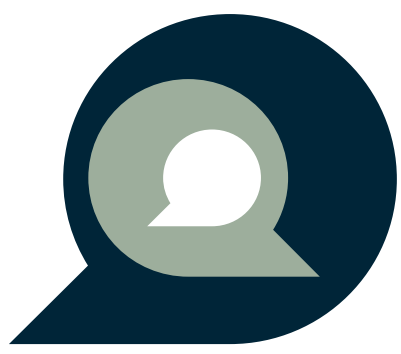

